\title{
Idade de Desmame e Suplementação no Desenvolvimento e em Características de Carcaças de Novilhos de Corte ${ }^{1}$
}

\author{
Luciane Salgueiro Pio de Almeida², José Fernando Piva Lobato ${ }^{3}$, Flávio Schramm Schenkel ${ }^{4}$
}

RESUMO - O experimento foi conduzido na Estação Experimental da Universidade Federal do Rio Grande do Sul, município de Eldorado do Sul, Brasil, a fim de avaliar o desempenho de 40 bezerros filhos de vacas cruzas Bos indicus $x$ Bos taurus até os dois anos de idade, desmamados precocemente (DP), com média de idade de 91 dias e mínimo de $70 \mathrm{~kg}$ de peso vivo, ou desmamados à idade convencional (DC), média de 170 dias de idade e peso médio de $131,2 \mathrm{~kg}$, suplementados ( $\mathrm{Su}$ ) ou não (NSu) com ração energético-protéica com $14 \%$ de proteína bruta e $75 \%$ de nutrientes digestíveis totais, durante 91 dias no primeiro inverno. O delineamento experimental utilizado foi o delineamento completamente casualizado. Os novilhos do DP foram mais leves até um ano de idade (DP=208,7 kg x $\mathrm{DC}=233,5 \mathrm{~kg})$. Aos 18-20 meses de idade, os novilhos não eram mais estatisticamente diferentes em seus pesos vivos (DP=279,9 kg x DC=292,5 kg). Ao abate, os pesos vivos médios foram de 432,3 kg (DC) e 414,0 kg (DP), não diferindo também no rendimento, acabamento, conformação e classificação das carcaças. O desmame precoce não impediu o desenvolvimento e o abate dos novilhos aos dois anos de idade. A suplementação no primeiro inverno não alterou o desempenho dos novilhos ao abate.

Palavras-chave: carcaça, idade de abate, idade de desmame, gado de corte, suplementação

\section{Effect of Weaning Age and Supplementation on the Growth and Carcass Characteristics of Beef Steers}

\begin{abstract}
The experiment run at the Agronomic Experimental Station of the Federal University of Rio Grande do Sul, located in the district of Eldorado do Sul, Brazil, to evaluate the performance of 40 crossbred Bos indicus x Bos taurus calves until two years old, early weaned (EW) with average age of 91 days and minimum liveweight of $70 \mathrm{~kg}$, or weaned at conventional age (CW), averaging 170 days old and liveweight of $131.2 \mathrm{~kg}$, supplemented $(\mathrm{Su})$ or not $(\mathrm{NSu})$ with energy-protein diet with $14 \%$ crude protein and $75 \%$ total digestible nutrients during 91 days in the first winter. A completely randomized experimental design was used. EW steers were

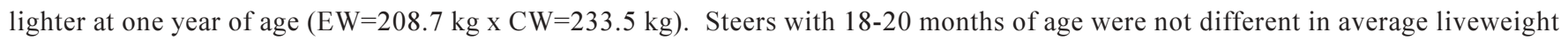
$(E W=279.9 \mathrm{~kg} \times \mathrm{CW}=292.5 \mathrm{~kg})$. Steers were slaughtered at average liveweights of CW=432.3 kg and EW=414.0 kg. Early weaning did not affect performance and carcass characteristics of steers with two years old. Supplementation in the first winter also did not affect performance of steers at slaughter.
\end{abstract}

Key Words: beef cattle, carcass, slaughter age, supplementation, weaning age

\section{Introdução}

O desmame precoce é uma técnica utilizada para aumentar os índices reprodutivos do rebanho de cria, com a redução da demanda energética da vaca pela suspensão do aleitamento. A eficiência da transformação de forragem em leite e este em crescimento do bezerro é de apenas 5 a 7\% (Rovira, 1996).

Entretanto, a vantagem energética e reprodutiva para as fêmeas não pode prejudicar o desenvolvimento dos bezerros. Segundo Restle et al. (1999b), quando o consumo de leite é cortado pelo desmame precoce, o bezerro, devido às condições de rúmen, principalmente a baixa capacidade física, não consegue retirar do pasto ingerido a quantidade necessária de nutrientes para manter o mesmo ritmo de ganho de peso que vinha mantendo ao pé da vaca.

$\mathrm{O}$ efeito do desmame precoce sobre a fertilidade das vacas consiste no incremento dos índices reprodutivos apenas pelo fato de cortar abruptamente as exigências nutricionais da lactação. Entretanto, a resposta em termos de ganho de peso dos bezerros está condicionada ao tipo de alimentação (Rovira, 1996).

Poli et al. (1979) desmamaram bezerros Hereford aos 205 dias (DC) em 02/05 e aos 107 dias (DP) de idade em 10/01. Os bezerros do DP receberam $2 \mathrm{~kg} /$

\footnotetext{
${ }^{1}$ Parte da tese na Faculdade de Agronomia - UFRGS do $1^{\circ}$ autor como um dos requisitos para obtenção do título de Mestre em Zootecnia, Área de Concentração Produção e Manejo Animal.

${ }^{2}$ Médica veterinária, M.Sc. em Zootecnia - UFRGS, Porto Alegre, RS. E.mail: milaemar@ig.com.br

${ }^{3}$ Prof. Adjunto IV, PhD. Departamento de Zootecnia - UFRGS. Bolsista do CNPq. E.mail: lobato@orion.ufrgs.br

${ }^{4}$ Pesquisador Associado da Universidade de Guelph, ON, Canadá. E.mail: schenkel@uoghelph.ca
} 
cab/dia de ração com $14 \%$ de proteína bruta (PB) no período de $03 / 01$ a 02/05/78. Os autores não determinaram diferença estatística em peso vivo (PV) dos bezerros quando do DC, sendo as médias de PV 169,2 e 149,0 kg para o DC e DP, respectivamente.

Moraes \& Lobato (1993) desmamaram bezerros aos 147 dias (D5) e 209 dias (D7) de idade, abatendo os novilhos de ambos tratamentos com aproximadamente 16 meses de idade e média de $400 \mathrm{~kg}$ de PV.

Albospino \& Lobato (1994) estudaram o efeito do desmame de bezerros aos 100 dias (S1) e 150 dias (S2) de idade sobre o desenvolvimento até o abate aos 24/26 meses de idade. Os pesos vivos no frigorífico e os rendimentos de carcaça dos novilhos foram de $400 \mathrm{~kg}$ e $56,1 \%$, para $\mathrm{S} 1$, e de $398 \mathrm{~kg}$ e $56,1 \%$, para $\mathrm{S} 2(\mathrm{P}>0,05)$. Concluíram ser viável o abate de novilhos precoces de bezerros desmamados aos 100 dias de idade mediante um eficiente programa sanitário e nutricional, com a utilização de pastagens de azevém e trevo vesiculoso cv. Yuchi nos dois primeiros inverno/primavera.

Em experimento realizado com animais Hereford, $1 / 2$ Jersey $1 / 2$ Hereford e $5 / 8$ Hereford $3 / 8$ Nelore, filhos de novilhas prenhes aos 14 meses de idade e confinados por 193 dias com ração com $12 \%$ de proteína bruta (PB), Restle et al. (1999c) abateram os novilhos com 14 meses de idade, média de $195 \mathrm{~kg}$ de carcaça, concluindo ser viável o abate precoce de novilhos filhos de vacas primíparas aos 24 meses.

Animais jovens após o desmame fazem ganhos mais eficientes, pois apresentam maior crescimento de tecido muscular em relação ao tecido adiposo. Entretanto, levam mais dias até atingir um grau de acabamento de carcaça aceitável. Por isso, é aconselhável recriar bezerros em pastagens ou suplementálos no inverno (fase do desmame ao sobreano) (Gottschall, 1999).

Restle et al. (1999e) estudaram as características de carcaça de machos 5/8 Hereford 3/8 Nelore desmamados em duas idades, aos 72 (T72) e aos 210 (T210) dias. Os bezerros foram terminados em confinamento e abatidos aos 14 meses de idade. Não determinaram diferença significativa quanto ao peso de fazenda e rendimento de carcaça quente $(\mathrm{T} 72=$ $424 \mathrm{~kg}$ e $54,7 \%$; T2 $10=406 \mathrm{~kg}$ e $54,4 \%$ ) e peso de carcaça fria $(\mathrm{T} 72=224 \mathrm{~kg}$ e $\mathrm{T} 210=214 \mathrm{~kg})$. A espessura de gordura de cobertura não diferiu significativamente entre os dois grupos de carcaça, sendo 4,6 e 4,21 mm, respectivamente para $\mathrm{T} 72 \mathrm{e}$ $\mathrm{T} 210$. Os resultados mostraram que animais desma- mados aos 72 dias de idade apresentam carcaça compatível aos desmamados com 210 dias, com peso e acabamento dentro dos limites exigidos pelos frigoríficos.

O objetivo deste trabalho foi estudar os efeitos de duas idades de desmame, precoce e convencional, e o da suplementação energético-protéica no primeiro inverno-primavera no desenvolvimento dos machos até os dois anos de idade, conduzidos nos dois primeiros invernos/primaveras em pastagens de ciclo hiberno/primaveril.

\section{Material e Métodos}

O experimento foi conduzido na Estação Experimental Agronômica da Universidade Federal do Rio Grande do Sul, situada no Km 146 da Br 290, município de Eldorado do Sul, pertencente à região da Depressão Central do Estado do Rio Grande do Sul, no período de janeiro de 1999 a novembro de 2000. Foram utilizados 40 bezerros, filhos de vacas cruzas Bos indicus x Bos taurus, nascidos no período de 01/09 a 14/11/1998.

O clima da região é do tipo $\mathrm{Cfa}$ (subtropical úmido), segundo a classificação de Köppen (Bergamaschi \& Guadagnin, 1990). A precipitação média anual é de 1400 mm, com menor incidência nos meses de verão. O solo pertence à unidade de mapeamento São Jerônimo, classificado como laterítico bruno avermelhado distrófico (Brasil, 1973). Possui textura franco argilosa à argilosa, sendo solos ácidos, pobres em matéria orgânica, com pH em torno de 5,0.

A pastagem nativa é composta por espécies dos gêneros Andropogon, Axonopus e Paspalum, com leguminosas como Trifolium polimorphum e Desmodium incanum. Há espécies cespitosas de baixo valor forrageiro como Eryngium horridum (caraguatá), Baccharis trimera (carqueja) e Baccharis coridifolia (mio-mio) (Boldrini, 1993).

As estimativas da disponibilidade de forragem foram realizadas a cada 28 dias pelo método comparativo (Haydock \& Shaw, 1975). Foram realizados cinco cortes de $0,25 \mathrm{~m}^{2}$ rentes ao solo, sendo pontuados de um (menor disponibilidade forrageira) a cinco (máxima disponibilidade forrageira). Foram feitas 30 avaliações visuais aleatórias e pontuadas de um a cinco de acordo com os cortes previamente realizados no potreiro. As amostras foram acondicionadas em sacos de papel, identificadas de acordo com o potreiro e o dia da coleta. No Laboratório de Nutrição

R. Bras. Zootec., v.32, n.6, p.1713-1721, 2003 (Supl. 1) 
Animal da Faculdade de Agronomia da Universidade Federal do Rio Grande do Sul, foram pesadas (matéria verde) e mantidas em estufa $\left(60^{\circ} \mathrm{C}\right)$ por 72 horas, sendo pesadas novamente para determinação da matéria seca. Após moído o material, o teor de nitrogênio foi determinado pelo método de Kjeldahl, sendo multiplicado por 6,25 para ser obtido o teor de PB da amostra (A.O.A.C., 1975).

Os tratamentos experimentais foram:

- Desmame precoce (DP) - 24 bezerros desmamados em 05/01/99 com idade média de 91 dias e peso mínimo de $70 \mathrm{~kg}$;

- Desmame convencional (DC)- 16 bezerros desmamados em 26/03/99 com idade média de 170 dias e peso médio de $131,2 \mathrm{~kg}$;

- Suplementado (Su) - metade dos animais de cada desmame foi suplementado com ração comercial energético-protéica, com $14 \%$ de PB e $75 \%$ de nutrientes digestíveis totais com uma oferta de até $1,5 \%$ do peso vivo/dia no período de $01 / 07$ a 30/09/99, sobre pastagem nativa melhorada de aveia (Avena sativa), azevém (Lolium multiflorum Lam.) e trevo vesiculoso (Trifolium vesiculosum cv. Yuchi);

- Não suplementado (NSu) - metade dos tratamentos DP e DC não foram suplementados, sendo mantidos na mesma pastagem nativa melhorada $\mathrm{e}$ mesma disponibilidade.

Os bezerros do DP foram suplementados logo após o desmame com ração comercial (Bünge Alimentos) com $18 \%$ de PB, na base de $1,5 \%$ do peso vivo durante 60 dias em campo nativo. Após o desmame dos bezerros do DC, ambos os lotes foram reunidos e mantidos em campo nativo. No período de 25/05/99 a 06/11/99 estiveram em pastejo na pastagem nativa melhorada. Durante 90 dias (01/07 a 30/09/99) metade dos bezerros de cada tratamento foi suplementado com concentrado comercial conforme descrito anteriormente. A outra metade não foi suplementada (NSu). No período de primavera-verão-outono, os novilhos estiveram em campo nativo, retornando à mesma pastagem nativa melhorada de 19/05 a 06/11/00, quando foram abatidos.

Cada carcaça foi avaliada visualmente para determinação do grau de acabamento, em milímetros de gordura, da conformação $(C=$ Convexa, $\mathrm{Sc}=$ subconvexa, $\mathrm{Re}=$ retilínea, $\mathrm{Sr}=$ sub-retilínea e $\mathrm{Co}=$ côncava) e a classificação final. Segundo o Sistema Nacional de Tipificação de Carcaças Bovinas (Brasil, 1989) a carcaça é considerada "Cota
Hilton" (classificação superior), quando provém de um animal de até quatro dentes definitivos, sem queda dos segundos médios da primeira dentição, apresenta acabamento entre 2 a $4 \mathrm{~mm}$ de gordura, conformação Re, Sc ou C, pesando no mínimo $210 \mathrm{~kg}$ de peso líquido de carcaça quente para machos inteiros ou castrados e $180 \mathrm{~kg}$ para as fêmeas. Além destes parâmetros visuais, foram determinados os pesos líquidos e os rendimentos de carcaça quente individualmente.

O delineamento experimental utilizado foi o completamente casualizado. Os dados foram analisados pelo General Linear Models (GLM) do programa estatístico Statistical Analysis System (SAS, 1996).

As variáveis de resposta contínua com distribuição pressuposta normal relativas aos bezerros, quais sejam: peso e ganho médio diário (GDM) em kg foram analisadas pelo procedimento General Linear Models (GLM) por análise de (co)variância, considerando-se o desbalanceamento do número de observações. As diferenças entre as médias ajustadas foram testadas pelo teste de Scheffé. O modelo utilizado foi o seguinte:

$Y_{h i j k l}=\mu+D_{h}+G_{i}+S_{j}+S_{u_{k}}+D_{h i}+D S u_{h k}$
$+G_{h u_{i k}}+D_{\text {DSu }}$ hik $_{1}+\beta_{1}(I V)+\beta_{2}\left(I^{2}\right)+\beta_{3} D J P+$
$\beta_{4}\left(D^{2}\right)+e_{h i j k l}$ em que: $Y_{\text {hijkl }}=$ variável resposta associada ao 1ésimo animal; $\mu$ = média geral; $D_{h}=$ efeito fixo do h-ésimo tipo de desmame; $G_{i}=$ efeito fixo do iésimo grupo genético materno; $\mathrm{S}_{\mathrm{j}}=$ efeito fixo do $\mathrm{j}$ ésimo sexo dos bezerros; $\mathrm{Su}_{\mathrm{k}}=$ efeito fixo do késimo nível de suplementação; $\mathrm{DG}_{\mathrm{hi}}=$ efeito fixo da interação entre o h-ésimo tipo de desmame e o i-ésimo grupo genético materno; $\mathrm{DSu}_{\mathrm{hk}}=$ efeito fixo da interação entre o h-ésimo tipo de desmame e o k-ésimo nível de suplementação; $\mathrm{GSu}_{\mathrm{ik}}=$ efeito fixo da interação entre o i-ésimo grupo genético materno e o k-ésimo nível de suplementação; $\mathrm{DGSu}_{\text {hik }}=$ efeito fixo da interação tríplice entre o h-ésimo tipo de desmame, o i-ésimo grupo genético materno e o k-ésimo nível de suplementação; IV = idade da vaca; DJP = data juliana do parto (anterior); $\beta_{1}$ e $\beta_{3}$ = coeficientes de regressão linear; $\beta_{2}$ e $\beta_{4}=$ coeficientes de regressão quadrático; $\mathrm{e}_{\mathrm{hijkl}}=$ efeito residual aleatório.

A variável $\mathrm{S}_{\mathrm{u}}$ (suplementação) foi incluída somente nas análises em que a variável resposta foi medida após a aplicação deste tratamento.

As variáveis de resposta contínua com distribuição pressuposta normal do peso dos novilhos na

R. Bras. Zootec., v.32, n.6, p.1713-1721, 2003 (Supl. 1) 
Estação Experimental, peso líquido de carcaça quente e rendimento de carcaça quente, foram analisadas pelo procedimento General Linear Models (GLM) por análise de (co)variância, considerando-se o desbalanceamento do número de observações. Foram testados os principais efeitos e retirados do modelo os que apresentaram baixos efeitos. O modelo para análise do peso na Estação Experimental, peso líquido de carcaça quente e rendimento da carcaça quente foi:

$$
\mathrm{Y}_{\mathrm{hij}}=\mu+\mathrm{D}_{\mathrm{h}}+\mathrm{Su}_{\mathrm{i}}+\mathrm{DSu}_{\mathrm{hi}}+\mathrm{e}_{\mathrm{hij}}
$$

em que: $Y_{\text {hij }}=$ variável resposta associada ao j-ésimo animal; $\mu=$ média geral; $D_{h}=$ efeito fixo do h-ésimo tipo de desmame; $\mathrm{Su}_{\mathrm{i}}=$ efeito fixo do i-ésimo nível de suplementação; $\mathrm{DSu}_{\mathrm{hi}}=$ efeito fixo da interação entre o h-ésimo tipo de desmame e o i-ésimo nível de suplementação; $\mathrm{e}_{\mathrm{hij}}=$ efeito residual aleatório.

As variáveis classificatórias da carcaça quais sejam: acabamento, em milímetros de gordura, conformação e classificação "Cota Hilton" ou carcaça comum foram analisadas pelo teste do Qui-Quadrado (Gomez \& Gomez, 1984), segundo o modelo abaixo:

$$
\mathrm{Y}_{\mathrm{hij}}=\mu+\mathrm{D}_{\mathrm{h}}+\mathrm{Su}_{\mathrm{i}}+\mathrm{e}_{\mathrm{hij}}
$$

em que: $\mathrm{Y}_{\text {hij }}=$ variável resposta associada ao j-ésimo animal; $\mu=$ média geral; $D_{h}=$ efeito fixo do h-ésimo tipo de desmame; $\mathrm{Su}_{\mathrm{i}}=$ efeito fixo do i-ésimo nível de suplementação; $\mathrm{e}_{\mathrm{hij}}=$ efeito residual aleatório.

\section{Resultados e Discussão}

Na Tabela 1, estão apresentados em kg os pesos médios do DP (05/01), DC (26/03), início (01/07) e final (30/09) da suplementação, ao um ano de idade (06/11/99), e GMD dos bezerros, segundo os tratamentos: DP, DC, Su, NSu, DCNSu e DPSu.

Os animais do DP apresentaram menor GMD de 05/01 a 26/03/98. Isso pode ser devido ao stress do desmame, aos potreiros de campo nativo com baixa qualidade forrageira $(5,36 \%$ de $\mathrm{PB})$, em que pese a alta disponibilidade (1976,0 kg/MS/ha), além de não apresentarem seu sistema digestivo completamente desenvolvido, não conseguindo retirar do pasto a quantidade de nutrientes suficiente para manter os ganhos de peso que apresentavam ao pé da vaca (Restle el al., 1999b).

Sá et al. (1997) desmamaram bezerros Red Angus $\mathrm{x}$ Nelore aos 60 dias (D60) e aos 120 dias (D120), obtendo GMD de $0,381 \mathrm{~kg}$ e $0,614 \mathrm{~kg}$ para os tratamentos D60 e D120, respectivamente. Esses ganhos estão de acordo com os obtidos neste experimento no período do DP ao DC.

No tocante ao aparelho digestivo, o ruminante apresenta duas fases funcionais: a de não ruminante e a de ruminante. A idade ao início da ruminação caracteriza-se pelo momento em que o animal passa

Tabela 1 - Pesos médios, em kg, no desmame precoce (DP-05/01/99), no desmame convencional (DC -26/03/99), início $(01 / 07 / 99)$ e final $(30 / 09 / 99)$ da suplementação, ao um ano de idade (06/11/99), e ganhos médios diários (GMD), segundo os tratamentos, desmame precoce (DP), convencional (DC), suplementado (Su), não suplementado (NSu), desmame convencional não suplementado (DCNSu) e desmame precoce suplementado (DPSu)

Table 1 - Mean liveweights, in $\mathrm{kg}$, at the early weaning (EW-99/01/05), at the conventional weaning (CW-99/03/26), in the beginning (99/07/01) and end (99/09/30) of supplementation, with one year of age (99/11/06), and average daily liveweight gain (ADG), as treatments, early weaning (EW), conventional (CW), supplemented (Su), not supplemented (NSu), not supplemented

\begin{tabular}{|c|c|c|c|c|c|c|c|c|}
\hline \multirow[t]{2}{*}{$\begin{array}{l}\text { Tratamento } \\
\text { Treatment }\end{array}$} & \multicolumn{2}{|c|}{$\begin{array}{c}\text { Peso } \\
\text { Liveweight }\end{array}$} & \multirow[t]{2}{*}{$\begin{array}{l}\mathrm{GMD}^{1} \\
A D G^{l}\end{array}$} & \multirow{2}{*}{$\begin{array}{c}\text { Peso } \\
\text { Liveweight } \\
01 / 07 / 99\end{array}$} & \multirow[t]{2}{*}{$\begin{array}{l}\mathrm{GMD}^{2} \\
A D G^{2}\end{array}$} & \multicolumn{2}{|c|}{$\begin{array}{c}\text { Peso } \\
\text { Liveweight }\end{array}$} & \multirow[t]{2}{*}{$\begin{array}{l}\mathrm{GMD}^{3} \\
A D G^{3}\end{array}$} \\
\hline & 05/01/99 & 26/03/99 & & & & $30 / 09 / 99$ & $06 / 11 / 99$ & \\
\hline $\mathrm{DP}(E W)$ & $82,7^{\mathrm{a}}$ & $112,7^{\mathrm{a}}$ & $0,381^{\mathrm{a}}$ & $126,8^{\mathrm{a}}$ & $0,684^{\mathrm{a}}$ & $189,9^{\mathrm{a}}$ & $207,1^{\mathrm{a}}$ & $0,467^{\mathrm{a}}$ \\
\hline $\mathrm{DC}(C W)$ & $83,0^{\mathrm{a}}$ & $131,2^{b}$ & $0,603^{b}$ & $139,5^{\mathrm{b}}$ & $0,717^{\mathrm{a}}$ & $205,9^{b}$ & $230,0^{\mathrm{b}}$ & $0,651^{b}$ \\
\hline $\mathrm{Su}(\mathrm{Su})$ & - & - & - & 133,4 & $0,779^{a}$ & $205,1^{\mathrm{a}}$ & - & - \\
\hline $\mathrm{NSu}(N S u)$ & - & - & - & 133,5 & $0,621 b$ & $190,6^{\mathrm{b}}$ & - & - \\
\hline $\mathrm{DCNSu}(N S u C W)$ & - & - & - & - & - & 196,1 & 218,8 & $0,613^{\mathrm{a}}$ \\
\hline $\mathrm{DPSu}(S u E W)$ & - & - & - & - & - & 194,5 & 209,7 & $0,410^{\mathrm{b}}$ \\
\hline
\end{tabular}
conventional weaning (NSUCW) and supplemented early weaning (SuEW)

Médias seguidas de mesma letra, na mesma coluna, dentro de tipo de desmame ou suplementação, não diferem (P>0,05) pelo F-teste. Means followed by the same letter, in a column, in the weaning or supplementation treatment, do not differ ( $P>.05)$ by $F$-test.

1 GMD de 06/11/99 a 05/01/99 (ADG from $11 / 06 / 99$ to $01 / 05 / 99$ ).

2 GMD de $06 / 11 / 00$ a 19/05/00 (ADG from $11 / 06 / 00$ to 05/19/00).

3 GMD de 06/11/00 a 05/01/99 (ADG from 11/06/00 to 01/05/99). 
da primeira à segunda fase, fenômeno relacionado diretamente com a função dos pré-estômagos e com o estado de saúde do animal (Bacalhau et al., 1992). Estes autores determinaram para terneiros Guzerá e Gir médias de idade e peso ao início da ruminação de 27,67 dias e $44,55 \mathrm{~kg}$ e 25,69 dias e $38,28 \mathrm{~kg}$, respectivamente.

Além do período estressante pelo qual passaram os animais do DP, o consumo de concentrado fornecido por 60 dias no pós-desmame acarretou interrupções importantes de consumo. Estas interrupções consistem em reações comportamentais ligadas a distúrbios digestivos (diminuições acentuadas de $\mathrm{pH}$ ruminal devidas à ingestão de elevados teores de glicídios solúveis), os quais se manifestam pela redução ou supressão do consumo dos alimentos a eles relacionados (Abreu da Silva et al., 1997).

A transição da fase de não ruminante para ruminante é dependente da dieta que os terneiros ingerem. Terneiros recebendo leite e feno à vontade apresentaram contração ruminal desde três semanas de idade devido ao consumo de matéria seca e ácidos graxos voláteis (AGVs). Os AGVs permitem um importante desenvolvimento da camada mucosa e o crescimento das papilas. O feno causa o desenvolvimento da camada muscular (Ruckebusch, 1988).

Durante a amamentação, a fonte de energia e proteína provém da absorção intestinal de leite ou substitutos. Entretanto, o desmame causa alterações fundamentais na disponibilidade de nutrientes. Após o desmame, a energia origina-se primariamente da fermentação ruminal e absorção protéica nos intestinos de proteínas não-degradadas e microbianas (Funaba et al., 1994).

Quando o consumo de leite é cortado pelo desmame precoce, o bezerro, devido às condições de rúmen, principalmente a baixa capacidade física, não consegue retirar do pasto ingerido a quantidade necessária de nutrientes para manter o mesmo ritmo de ganho de peso que vinha mantendo ao pé da vaca (Restle et al., 1999b).

Funaba et al. (1994) estudaram o efeito do desmame precoce com 5 e 11 semanas de idade em bezerros da raça Holandês, tendo observado que a variação no peso vivo do desmame com cinco semanas foi menor que o grupo do desmame às 11 semanas. Entretanto, o consumo de concentrado aumentou rapidamente após o desmame com cinco semanas, tendo o consumo de nutrientes digestíveis totais também sido levemente menor nas semanas um a seis pós-desmama $(0,21$ e $0,26 \mathrm{~kg} / \mathrm{dia})$, que o desmame com 11 semanas. A digestibilidade da matéria seca e nitrogênio foram menores a uma semana, atingindo um platô na quinta semana para o desmame com cinco semanas. Os autores concluíram que, apesar de receberem concentrado contendo alta proteína bruta e alto nível de nutrientes digestíveis totais, os bezerros podem não aproveitar os nutrientes adequadamente. A maturação da digestão ruminal aumentou do desmame até oito semanas.

Sampedro (1993) desmamou bezerros com três meses de idade (DP) e peso médio de $105+/-15 \mathrm{~kg}$, tendo observado os bezerros do DP alcançarem GMD no período do DP ao do convencional de $0,520 \mathrm{~kg}$, enquanto os bezerros mantidos com as vacas (DC) apresentaram GMD de 0,870 kg. Estes dados reforçam os resultados obtidos em favor do DC no período inicial do experimento.

Resultados semelhantes foram encontrados por Antunes et al. (2000), que forneceram 0; 0,75 e 1,5\% do peso vivo em grão de sorgo moído a novilhos com 12 meses de idade, mantidos em pastagem natural melhorada com a inclusão de Lotus subbiflorum. Os animais apresentaram GMDs variando de 0,36 a $0,76 \mathrm{~kg}$, havendo efeito linear entre o GMD e o nível de suplemento energético. Estes GMDs foram tão baixos quanto os obtidos neste experimento. Os autores relatam que, devido à ocorrência de uma estiagem em outubro, a altura da pastagem declinou acentuadamente desde o início do experimento, passando de 10 a $13 \mathrm{~cm}$ para 2 a $3 \mathrm{~cm}$, o que deve ter limitado o ganho de peso animal.

Restle et al. (2000) encontraram efeito da suplementação no ganho de peso de novilhos de 1,5 anos recebendo $0 ; 0,6 ; 0,9$ e $1,2 \%$ do peso vivo de sorgo triturado, em pastejo de aveia e azevém durante quatro horas por dia. Foram observados GMD de 0,$986 ; 1,390 ; 1,386$ e $1,332 \mathrm{~kg} /$ dia para os níveis crescentes de suplemento. Esses desempenhos alcançados são superiores aos obtidos nesse trabalho, próprios de novilhos, categoria animal que apresenta GMDs superiores aos encontrados para bezerros (Restle et al., 1998) e ao tipo de suplemento utilizado, pois a pastagem de inverno apresenta alta digestibilidade, alto teor protéico e baixo teor de fibras (Restle et al., 1999a), exigindo um suplemento energético para melhores ganhos de peso.

Aroeira \& Rosa (1989) também observaram desempenhos inferiores aos deste experimento para machos da raça Nelore desmamados aos três (D3),

R. Bras. Zootec., v.32, n.6, p.1713-1721, 2003 (Supl. 1) 
cinco (D5) ou aos sete (D7) meses de idade. Aos 365 dias de idade, os pesos foram 145,8; 155,4 e 171,8 kg para os tratamentos, respectivamente. O tratamento D3 foi estatisticamente inferior ao D7. As diferenças observadas entre os experimentos podem ser explicadas pelas diferenças genéticas dos animais, ambientais e nutricionais das condições experimentais.

Os GMDs no primeiro outono-inverno-primavera são observados no período de 01/07 a 06/11. Os tratamentos DC e Su foram superiores aos DP e NSu em peso vivo. Analisando o GMD2, observa-se que não houve diferença significativa entre o tipo de desmame, mas o grupo Su apresentou maior GMD em relação ao $\mathrm{NSu}(0,779 \times 0,621 \mathrm{~kg}$, respectivamente).

Os pesos a um ano de idade para DCNSu, DCSu, DPNSu e DPSu foram 21 8,8; 241,2; 204,6 e 209,7 kg, respectivamente (Tabela 1). Estes dados mostram que o DCSu foi superior estatisticamente a todos os outros grupos, sendo que o DPSu não diferiu significativamente do DCNSu, mostrando bezerros desmamados precocemente e suplementados durante o inverno (julho a setembro) com desempenhos a um ano de idade semelhantes ao grupo desmamado em idade convencional e não suplementado.

A recuperação de desenvolvimento apresentada pelo grupo do DPSu é denominada crescimento compensatório, evento observado em animais que sofrem certa restrição nutricional. Esta restrição não significa perda de peso, e sim redução no ganho apresentado pelos animais submetidos a uma dieta nutricionalmente limitada.

Constam na Tabela 2 os pesos médios e GMD no DP (05/01/99), um ano de idade (06/11/99), 18 meses $(19 / 05 / 00)$ e aos dois anos de idade (06/11/00), segundo os tratamentos de DP e DC.
Harvey \& Burns (1988) encontraram ganhos semelhantes para bezerros Simmental x Hereford desmamados com 150 dias de idade (DP) e mantidos em milheto aos obtidos para bezerros em campo nativo e desmamados aos sete meses (DC). Os ganhos de peso nos meses de julho a setembro (verão no Hemisfério Norte) foram de $0,93 \mathrm{~kg} \mathrm{e}$ $1,10 \mathrm{~kg}$ para o DP e o DC, respectivamente. Esses ganhos são muito superiores aos obtidos neste experimento, devido à alta digestibilidade do milheto disponível aos animais, traduzindo em maior ganho de peso a melhor qualidade forrageira a que foram submetidos os bezerros.

Müller \& Primo (1986), trabalhando com bezerros da raça Hereford desmamados à idade convencional e com acesso à pastagem cultivada no primeiro e segundo invernos pós-desmame, obtiveram $430 \mathrm{~kg}$ de peso vivo aos dois anos.

Durante o período de 19/05/00 a 06/11/00, outono-inverno-primavera, os animais do DP e do DC não diferiram em $\operatorname{GMD}(0,670 \mathrm{~kg} \mathrm{x} 0,747 \mathrm{~kg}$, respectivamente).

Os animais do DP mesmo apresentando menores GMD nos períodos do DP ao DC e do final da suplementação a um ano de idade, pela utilização de pastagem melhorada nos dois períodos de inverno/ primavera, obtiveram desempenhos semelhantes ao grupo DC, sendo abatidos aos dois anos de idade com peso médio de $393,8 \mathrm{~kg}$.

Albospino \& Lobato (1994), ao analisarem os machos submetidos ao desmame aos 100 dias ou 150 dias de idade, obtiveram GMD de $0,445 \mathrm{~kg}$ e $0,477 \mathrm{~kg}$ até o abate aos dois anos de idade, com 400 e $398 \mathrm{~kg}$ de peso vivo, respectivamente.

Na Tabela 3, apresentam-se os pesos vivos mé-

Tabela 2 - Pesos médios e ganhos médios diários (GMD) no DP (05/01/99), um ano de idade (06/11/99), 18 meses $(19 / 05 / 00)$ e aos dois anos de idade $(06 / 11 / 00)$, segundo os tratamentos, desmame precoce (DP) ou convencional (DC)

Table 2 - Liveweights and average daily liveweight gain (ADG) at EW (01/05/99), one year of age (11/06/99), 18 months (05/19/00) and two years of age (11/06/00), as early (EW) or conventional weaning (CW)

\begin{tabular}{|c|c|c|c|c|c|c|c|}
\hline \multirow{3}{*}{$\begin{array}{l}\text { Tratamento } \\
\text { Treatment }\end{array}$} & \multirow{2}{*}{\multicolumn{3}{|c|}{$\begin{array}{c}\text { Peso } \\
\text { Liveweight }\end{array}$}} & \multirow{3}{*}{$\begin{array}{l}\mathrm{GMD}^{1} \\
A D G^{l}\end{array}$} & \multirow{3}{*}{$\begin{array}{c}\text { Peso } \\
\text { Liveweight } \\
06 / 11 / 00\end{array}$} & \multirow{3}{*}{$\begin{array}{l}\mathrm{GMD}^{2} \\
A D G^{2}\end{array}$} & \multirow{3}{*}{$\begin{array}{l}\mathrm{GMD}^{3} \\
A D G^{3}\end{array}$} \\
\hline & & & & & & & \\
\hline & $05 / 01 / 99$ & $06 / 11 / 99$ & $19 / 05 / 00$ & & & & \\
\hline $\mathrm{DP}(E W)$ & $82,7^{\mathrm{a}}$ & $207,1^{\mathrm{a}}$ & $279,9^{\mathrm{a}}$ & $0,367^{\mathrm{a}}$ & $393,8^{a}$ & $0,670^{\mathrm{a}}$ & $0,463^{a}$ \\
\hline $\mathrm{DC}(C W)$ & $83,0^{\mathrm{a}}$ & $230,0^{\mathrm{b}}$ & $292,5^{\mathrm{a}}$ & $0,304^{\mathrm{a}}$ & $419,4^{\mathrm{a}}$ & $0,747^{\mathrm{a}}$ & $0,501^{\mathrm{a}}$ \\
\hline
\end{tabular}

Médias seguidas de mesma letra, na mesma coluna, não diferem $(P>0,05)$ pelo F-teste.

Means followed by the same letter, in a column, do not differ $(P>05)$ by F-test.

1 GMD de 06/11/99 a 05/01/99 (ADG from 11/06/99 to 01/05/99).

2 GMD de 06/11/00 a 19/05/00 (ADG from 11/06/00 to 05/19/00).

3 GMD de 06/11/00 a 05/01/99 (ADG from 11/06/00 to 01/05/99).

R. Bras. Zootec., v.32, n.6, p.1713-1721, 2003 (Supl. 1) 
dios na origem, pesos líquidos de carcaça quente (PLC) em kg e rendimento de carcaça quente (RCQ) em porcentagem dos novilhos e número de animais (N) do desmame precoce (DP), desmame convencional (DC), grupo suplementado (Su) e não suplementado (NSu) ao abate aos dois anos de idade.

A suplementação, da mesma forma que os GMD e pesos vivos aos dois anos de idade, não apresentou efeito significativo, não havendo interação entre o tipo de desmame e a suplementação realizada no primeiro inverno.

Resultados semelhantes ao deste experimento foram encontrados por Moraes \& Lobato (1993), ao abaterem novilhos Polled Hereford x Nelore desmamados em média com 147 dias de idade, com aproximadamente 16 meses de idade, média de $400 \mathrm{~kg}$ de peso vivo, demonstrando que com um bom nível nutricional pósdesmame é possível abater a menores idades novilhos desmamados aos cinco meses de idade.

Os resultados obtidos estão de acordo com os observados por Albospino \& Lobato (1994) os quais desmamaram bezerros aos 100 dias (D100) ou 150 (D150) dias de idade, abatidos aos dois anos com pesos líquidos de carcaças (224,5 kg, D100;223,1 kg, D150), e rendimento de carcaça de $56,1 \%$, ambos superiores aos encontrados neste experimento.

Novilhos cruza Charolês x Nelore foram desmamados aos 90 (T90) ou 210 (T210) dias, sendo terminados em pastagem cultivada de Avena strigosa + Lolium multiflorum + Trifolium vesiculosum $\mathrm{e}$ abatidos aos 24 meses de idade por Restle et al. (1999d). Os pesos na fazenda (T90 $=437 \mathrm{~kg}$ e
$\mathrm{T} 210=467 \mathrm{~kg}$ ), os rendimentos de carcaça quente $(\mathrm{T} 90=53,33 \%$ e T210 $=52,21 \%)$, os pesos de carcaça quente $(\mathrm{T} 90=233 \mathrm{~kg}$ e T210 $=244 \mathrm{~kg})$, a espessura de gordura de cobertura (T90 $=2,56 \mathrm{~mm}$ e $\mathrm{T} 210=2,27 \mathrm{~mm}$ ) e a conformação da carcaça não diferiram estatisticamente entre os dois tratamentos. Conforme os autores, o desmame precoce aos 90 dias não afetou as características de carcaça de novilhos abatidos aos 24 meses de idade, desde que as condições de alimentação sejam adequadas, o que está de acordo com o presente trabalho.

Apesar das diferenças observadas em termos de peso vivo e GMD entre as épocas de desmame até um ano de idade, os novilhos do DP alcançaram desempenhos ao abate estatisticamente semelhantes aos animais do DC.

Não houve efeitos significativos do tipo de desmame sobre as variáveis de acabamento de carcaça (em mm de gordura) e da conformação de carcaça, mostrando ter bezerros do DP acabamento e conformação de carcaça semelhantes ao grupo DC.

$\mathrm{O}$ acabamento de carcaça foi categorizado em 2 ou $3 \mathrm{~mm}$ de gordura, sendo que 32,5 e 45,0\% dos animais do DC e do DP apresentaram classificação visual de $3 \mathrm{~mm}$ de gordura, respectivamente.

Em termos de conformação, 57,5\% dos animais apresentaram classificação retilínea, 37,5\% foram sub-retilíneos e apenas $5 \%$ obtiveram conformação sub-convexa, não havendo diferença entre carcaças do DP e DC.

Brondani et al. (2000) não observaram diferença significativa na conformação e na espessura de gor-

Tabela 3 - Pesos vivos médios na origem, pesos líquidos de carcaça quente (PLC) e rendimento de carcaça quente (RCQ) dos novilhos, número de animais (N) do desmame precoce (DP), desmame convencional (DC), grupo suplementado (Su) e não suplementado (NSu) ao abate aos dois anos de idade

Table 3 - Liveweights in the origin, net carcass weights (CNW) and steers dressed carcass (DC) and number of animals (N) as early weaning $(E W)$, conventional weaning (CW), supplemented group (Su), not supplemented (NSu) at slaugther with two years of age

\begin{tabular}{|c|c|c|c|c|c|}
\hline $\begin{array}{l}\text { Fator } \\
\text { Factor }\end{array}$ & $\begin{array}{c}\text { Tratamento } \\
\text { Treatment }\end{array}$ & $\mathrm{N}$ & $\begin{array}{c}\text { Peso na origem } \\
\text { Liveweight in the origin }\end{array}$ & $\begin{array}{c}\mathrm{PLC}(\mathrm{kg}) \\
C N W\end{array}$ & $\begin{array}{c}\mathrm{RCQ}(\%) \\
D C \\
\end{array}$ \\
\hline $\begin{array}{l}\mathrm{DP}(E W) \\
\text { Média }^{1} \text { (Mean) }\end{array}$ & & 24 & 414,0 & 208,0 & 50,22 \\
\hline $\mathrm{DC}(C W)$ & & 16 & 432,3 & 216,0 & 50,03 \\
\hline $\begin{array}{l}\text { Contraste } \\
\text { Contrast }\end{array}$ & $\begin{array}{c}\text { (DC-DP) } \\
C W-E W\end{array}$ & & $18,3 \mathrm{NS}$ & $8,0 \mathrm{NS}$ & $-0,19 \mathrm{NS}$ \\
\hline $\begin{array}{l}\text { Su } \\
\text { Média }^{1} \text { (Mean) }\end{array}$ & & 21 & 421,5 & 210,1 & 49,91 \\
\hline $\begin{array}{l}\mathrm{NSu} \\
\text { Contraste }\end{array}$ & $(\mathrm{Su}-\mathrm{NSu})$ & 19 & $\begin{array}{l}424,8 \\
-3,3 \mathrm{NS}\end{array}$ & $\begin{array}{l}213,9 \\
-3,8 \mathrm{NS}\end{array}$ & $\begin{array}{l}50,35 \\
-0,44 \mathrm{NS}\end{array}$ \\
\hline
\end{tabular}

\footnotetext{
${ }^{1}$ Média ajustada (Adjusted mean).

NS = Não significativo (not significant).
}

R. Bras. Zootec., v.32, n.6, p.1713-1721, 2003 (Supl. 1) 
dura subcutânea (3,4 e 4,3 mm) em novilhos recriados em campo nativo $(\mathrm{CN})$ ou pastagem (PC), respectivamente, abatidos com idade média de 1,5 anos. Os rendimentos observados foram de 52,9 e $55,7 \%$ para os grupos $\mathrm{CN}$ e $\mathrm{PC}$, respectivamente, dados superiores aos obtidos neste experimento.

Não houve efeitos estatísticos do tipo de desmame sobre os padrões de classificação quanto à classificação "Cota Hilton" ou carcaça comum. No presente experimento, nove carcaças do DC (22,5\%) foram classificadas "Cota Hilton", enquanto do tratamento DP 12 carcaças alcançaram a mesma classificação $(30,0 \%)$.

Desempenhos superiores foram obtidos por Albospino \& Lobato (1994), quando abateram novilhos aos dois anos de idade, obtendo $77 \%$ dos animais desmamados aos 100 dias de idade classificados como "Cota Hilton", enquanto dos animais desmamados aos 150 dias $66 \%$ alcançaram a mesma classificação.

\section{Conclusões}

Bezerros desmamados precocemente, manejados em pastagem melhorada no primeiro inverno/ primavera, apresentam desenvolvimento inferior aos desmamados a idade convencional, quando avaliados até um ano de idade.

Bezerros desmamados precocemente, suplementados com ração com $14 \%$ de PB durante três meses no primeiro inverno, apresentam peso semelhante aos bezerros desmamados a idade convencional e não suplementados, quando da avaliação a um ano de idade.

Bezerros suplementados com concentrado energético-protéico durante o primeiro inverno são mais pesados até um ano de idade, apresentando desenvolvimento semelhante ao grupo não suplementado aos dois anos.

Os novilhos do desmame precoce são abatidos aos 24-27 meses de idade com pesos vivos e características de carcaça semelhantes aos novilhos desmamados a idade convencional.

\section{Agradecimento}

Ao pesquisador da EMBRAPA/CNPPSULBagé/RS, Eduardo Salomoni, M.Sc., pelo auxílio na classificação das carcaças dos novilhos.

À Bünge Alimentos, pelo fornecimento da ração comercial energético-protéica, que possibilitou a realização da suplementação dos novilhos.

\section{Literatura Citada}

ABREU da SILVA, M.A.; COSTA, P.B.; LOBATO, J.F.P. et al. Influência da Presença de Animais Experientes sobre o Comportamento Alimentar de Bezerros Desmamados entre 45-85 dias de idade. In: CONGRESSO BRASILEIRO DE MEDICINA VETERINÁRIA, 25., 1997, Gramado. Anais... Porto Alegre: Sovergs, 1997. p.276.

ALBOSPINO, B.H.J.C.; LOBATO, J.F.P. Efeitos do desmame precoce de bezerros no desempenho até os 24-26 meses de idade. Revista Brasileira de Zootecnia, v. 23, n.4, p. 565$575,1994$.

ANTUNES, V.S.; FISCHER, V.; MORENO, C.B. et al. Efeitos de níveis crescentes de suplemento energético sobre o desempenho de bezerros de corte em pastejo. In: REUNIÃO DA SOCIEDADE BRASILEIRA DE ZOOTECNIA, 37., 2000, Viçosa, MG. Anais... Viçosa, MG: Sociedade Brasileira de Zootecnia, 2000. p.433.

AROEIRA, A.D.C.; ROSA, A.N. Efeito da idade de desmama sobre o desenvolvimento de bezerros nelore criados a campo. Pesquisa Agropecuária Brasileira, v.24, n.11, p.13491352, 1989.

ASSOCIATION OF OFICIAL ANALYTICAL CHEMIST AOAC. Official methods of analysis. 12.ed. Washington, DC.: Comitee on Editing Methods of Analysis, 1975. 109 p.

BACALHAU, A.S.; ALBUQUERQUE, R.P.F.; MARINHO, J.S. et al. Correlação entre peso ao nascer, idade e peso ao início da ruminação em bezerros zebu. Pesquisa Agropecuária Brasileira, v.27, n. 11, p.1527-1532, 1992.

BERGAMASCHI, H.; GUADAGNIN, M.R. Agroclima da Estação Experimental Agronômica. Porto Alegre: Universidade Federal do Rio Grande do Sul, 1990. 96p.

BOLDRINI, I.I. Dinâmica de vegetação de uma pastagem natural sob diferentes níveis de oferta de forragem e tipos de solos, Depressão Central, RS. Porto Alegre: Universidade Federal do Rio Grande do Sul, Porto Alegre, 1993. 262p. Tese (Doutorado em Zootecnia) - Universidade Federal do Rio Grande do Sul, Porto Alegre, 1993.

BRASIL. Ministério da Agricultura. Departamento Nacional de Pesquisa Agropecuária. Divisão de Pesquisa Pedológica. Levantamento de reconhecimento dos Solos do Estado do Rio Grande do Sul. Recife, 1973. 431p. (Boletim Técnico, 30)

BRASIL. Ministério da Agricultura. Portaria no 612, de 05 de outubro de 1989. Aprova o novo sistema nacional de tipificação de carcaças bovinas. Diário Oficial da União, Brasília, p.18146, 10 out. 1989. Seção 1.

BRONDANI, J.L.; RESTLE, J.; ALVES FILHO, D.C. et al. Avaliação dos aspectos quantitativos de carcaças de novilhos submetidos a diferentes níveis de alimentação na recria e terminação. In: REUNIÃO DA SOCIEDADE BRASILEIRA DE ZOOTECNIA, 37., 2000, Viçosa, MG. Anais... Viçosa, MG: Sociedade Brasileira de Zootecnia, 2000. p.346.

FUNABA, M.; KAGIYAMA, K.; IRIKI, T. et al. Changes in nitrogen balance with age in calves weaned at 5 or 6 weeks of age. Journal of Animal Science, v.72, n.3, p.732-738, 1994.

GOMEZ, K.A.; GOMEZ, A.A. Statistical procedures for agricultural research. 2.ed. New York: John \& Wiley, 1984. 680p.

GOTTSCHALL, C.S. Impacto nutricional na produção de carne - curva de crescimento. In: LOBATO, J.F.P.; BARCELLOS, J.O.J; KESSLER, A.M. et al. (Eds.) Produção de bovinos de corte. Porto Alegre: PUCRS, 1999. p.169-192.

HARVEY, R.W.; BURNS, J.C. Creep grazing and early weaning 
effects on cow and calf productivity. Journal of Animal Science, v.66, p.1109-1114, 1988.

HAYDOCK, K.P.; SHAW, N.H. The comparative yield method for estimating dry matter yield of pasture. Australian Journal of Experimental Agriculture and Animal Husbandry, v.15, n.1, p. 663-670, 1975.

MORAES, A.A.S.; LOBATO, J.F.P. Efeito de duas idades de desmame no desenvolvimento de bezerros de corte. Revista Brasileira de Zootecnia, v.22, n.6, p.885-892, 1993.

MÜLLER, L.; PRIMO, A.T. Influência do regime alimentar no crescimento e terminação de bovinos e na qualidade da carcaça. Pesquisa Agropecuária Brasileira, v.21, n.4, p.445-452, 1986.

POLI, J.L.E.H.; FERREIRA, F.J.; BRANCO, L.A.M. et al. Eficiência reprodutiva e ganho de peso de bovinos hereford submetidos ao desmame antecipado e em regime de suplementação alimentar. Anuário Técnico IPZFO, v.6, p.67-77, 1979.

RESTLE, J.; LUPATINI, G.C.; ROSO, C. et al. Eficiência e desempenho de categorias de bovinos de corte em pastagem cultivada. Revista Brasileira de Zootecnia, v.27, n.2, p.397404, 1998.

RESTLE, J.; ROSO, C.; SOARES, A.B. Produção animal e retorno econômico em misturas de gramíneas anuais de estação fria. Revista Brasileira de Zootecnia, v. 28, n.2, p.235243, 1999a.

RESTLE, J.; POLLI, V.A.; ALVES FILHO, D.C. et al. Desenvolvimento de bovinos de corte de diferentes grupos genéticos desmamados aos 3 ou 7 meses de idade. Revista Brasileira de Zootecnia, v.28, n.5, p.1023-1030, 1999b.

RESTLE, J.; BRONDANI, I.L.; FLORES, J.L.C. et al. Desempenho de genótipos de novilhos para abate aos catorze meses, gerados por fêmeas de dois anos. Pesquisa Agropecuária Brasileira, v.34, n.11, p.2123-2128, 1999c.

RESTLE, J.; VAZ, F.N.; PASCOAL, L.L. et al. Efeito do desmame precoce na carcaça de novilhos terminados em pastagem e abatidos aos 24 meses. Pesquisa Agropecuária Brasileira, v.34, n.11, p.2129-2136, 1999d.
RESTLE, J.; VAZ, F.N.; BRONDANI, I.L. et al. Estudo da carcaça de machos Braford desmamados aos 72 ou 210 dias, abatidos aos catorze meses. Pesquisa Agropecuária Brasileira, v.34, n.11, p.2137-2144, 1999e.

RESTLE, J.; EIFERT, E.C.; PASCOAL, L.L. et al. Ganho de peso de novilhos terminados aos 24 meses, pastejando aveia e azevém por quatro horas diárias, associadas à suplementação. In: REUNIÃO DA SOCIEDADE BRASILEIRA DE ZOOTECNIA, 37., 2000, Viçosa, MG. Anais... Viçosa, MG: Sociedade Brasileira de Zootecnia, 2000. p.450.

ROVIRA, J.M. Manejo nutritivo de los rodeos de cría en pastoreo. Montevideo: Hemisferio Sur, 1996. 288p.

RUCKEBUSCH, Y. Motility of the gastro-intestinal tract. In: CHURCH, D.C. (Ed.). The ruminant animal: digestive physiology and nutrition. New Jersey: Prentice Hall, 1988. p.64-107.

SÁ, I.G.; BARCELLOS, J.O.J.; LOBATO, J.F.P. et al. Efeito do desmame precoce sobre a variação de peso de vacas e bezerros de corte em três sub-épocas de parição. In: REUNIÃO DA SOCIEDADE BRASILEIRA DE ZOOTECNIA, 34., 1997, Juiz de Fora. Anais... Juiz de Fora: Sociedade Brasileira de Zootecnia, 1997. p.461.

SAMPEDRO, D. Efecto del destete precoz sobre la tasa de preñez y la ganancia de peso de los terneros. In: JORNADA DE DIFUSIÓN TÉCNICA DESTETE PRECOZ EN CRÍA VACUNA, 1993, Concepción del Uruguay. Resumos... Entre Rios: INTA, 1993. p.39-41.

STATISTICAL ANALYSIS SYSTEM - SAS. SAS/STAT user's guide. 11.ed. Cary: 1996. 